\title{
Modernizing State Public Health Enabling Statutes to Reflect the Mission and Essential Services of Public Health
}

\author{
Benjamin Mason Meier, LLM, MPhil, JD, Jacqueline Merrill, DNSC, RN, and Kristine M. \\ Gebbie, DrPH, RN
}

\begin{abstract}
It is unclear whether efforts of the past decade to modernize state public health statutes have succeeded in codifying into state law the currently understood mission and essential services of public health. Although many state health agencies may be operating in a manner consistent with these principles, their codification in state law is crucial for the sustainability of agency efforts in disease prevention and health promotion. This research examines the 50 state public health enabling statutes for their correspondence with the 6 mission statements and the 10 essential services of public health described in Public Health in America. This analysis finds that modernization efforts have not been universally effective in ensuring that the legislative basis of public health is commensurate with the accepted scope of authority necessary to support health agency performance. Given current imperatives for law modernization in public health, this analysis highlights the importance of model statutory language in facilitating the codification of the mission and essential services of public health in state law. As a result, this research provides the practice community with a research base to facilitate statutory reform and develops a framework for future scholarship on the role of law as a determinant of the public's health.
\end{abstract}

\section{Keywords}

essential services; mission; public health law; statutory modernization; Turning Point Model State Public Health Act

\begin{abstract}
Despite recent national emphasis on reforming public health statutory authority as part of modernizing the infrastructure for public health, ${ }^{1,2}$ it is unclear whether statutory reform efforts have succeeded in codifying the mission and essential services of public health into state law. This research examines the public health enabling statutes of each state, analyzing those statutes for their correspondence with the 6 mission descriptions and the 10 essential services of public health described in Public Health in America. ${ }^{3}$ Although many states have reformed the statutory basis of public health over the last decade to reflect contemporary public health practice, these modernization efforts have not been universally effective in ensuring that the legislative basis of public health is commensurate with the accepted scope of authority necessary to protect and support the public's health. With this research identifying a gap in state codification of the mission and essential services of public health in state law, additional analysis will be necessary to evaluate (1) the effects of modernized public health law on health agency performance and (2) the role of model public health laws in statutory modernization.
\end{abstract}




\section{Background}

The "essential services of public health," first documented in 1994 in Public Health in America, ${ }^{3}$ are the accepted standard for public health service provision at local, state, and federal levels. ${ }^{4}$ Developed by the Public Health Functions Steering Committee-drawing on earlier efforts to document the "core functions" of public health (assessment, policy development, and assurance $)^{5}$ - Public Health in America has memorialized, among other things, a mission statement and a list of 10 essential services of public health agencies, outlined in Table 1.

These essential services represent what a health agency must do to "promote physical and mental health and prevent disease, injury, and disability." On the basis of these essential services, a mission statement, if included in statute, provides a general statement of direction. As compared with an essential service, which specifies more narrowly what authority the legislature has assigned specifically to the health agency, a mission statement is a broad encapsulation of the purposes or goals of the agency. ${ }^{2}$

Although references to the mission statement and essential services have been ubiquitous in the public health practice literature in the past 15 years ${ }^{6}$-for example, forming the frameworks for pivotal practice documents such as the Operational Definition of Public Health developed by the National Association of County and City Health Officials ${ }^{7}$ - there was little initial discussion of how these principles would be incorporated into the legal frameworks that authorize governmental public health practice. Although many policy makers, scholars, and public health officials argued that state-based public health laws were ripe for reform, ${ }^{2,8}$ few studies had examined the enabling statutes that create state and local health agencies and empower them to prevent disease and promote health.

In the years following the publication of Public Health in America, however, burgeoning efforts arose to lay a research foundation for the codification of essential services through state public health "enabling statutes," the statutes that enumerate the powers, authorities, and responsibilities of health agencies. ${ }^{9-11}$ Seminal baseline research in 2000 documented that very few state health agencies operated under enabling statutes that incorporated essential public health services within the purview of their legislative authority. ${ }^{9}$ Viewing these enabling statutes as a reflection of constituency expectations (operating through the legislative authorization of public health practice), this research concluded that "[s]tate public health agencies working with constituencies to improve public health should include in their plans the development of a statutory framework suitable for operating in today's

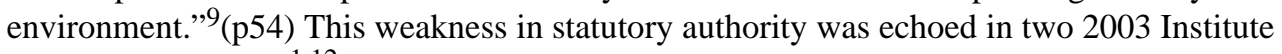
of Medicine reports, ${ }^{1,12}$ increasing the interest of state public health actors in modernizing the legal basis of their practice, and through this modernization, reforming laws to reflect contemporary scientific and constitutional standards of public health. ${ }^{13}$ In response to this emphasis on public health enabling statutes in facilitating efforts to strengthen the nation's public health infrastructure, legal modernization tools-most prominently, the Turning Point Model State Public Health Act (Turning Point Act), developed under the Robert Wood Johnson Foundation's Turning Point Project ${ }^{14}$ - proposed legislative language by which the mission and the essential services of public health could be incorporated into state public health enabling statutes. Combined with a national emphasis on statutory modernization through the Model State Emergency Health Powers Act, developed in the aftermath of the terrorist attacks of September 11, 2001 and ensuing anthrax dispersals, ${ }^{15,16}$ these model acts have served as guides for assessing gaps in state law and have provided statutory language for those states seeking law reform. ${ }^{17}$ 
Following a number of state law modernization efforts based on these model acts, ${ }^{18-20}$ decreasing fragmentation and inequality among public health services across the nation, no systematic research has been undertaken to assess the correspondence of these reformed statutes with the mission and essential services of public health expressed in Public Health in America. As the first part of a larger project to assess the degree of association between modern statutory language and health agency performance (as reported through the National Performance Standards Project ${ }^{21}$ ), this documentation of enabling statutes analyzes the effects of national modernization efforts on the scope and breadth of state authority for public health.

\section{Methods}

To assess the incorporation of the mission and essential services of public health in state public health law, this research seeks to

1. identify the extent to which state public health enabling statutes reflect the (a) mission and $(b)$ essential services of public health, consistent with the contemporary public health paradigm expressed in Public Health in America;

2. examine the extent to which this consistency with Public Health in America has changed in the past decade, in accordance with model legislative language expressed in the Turning Point Act, and

3. analyze the extent to which concepts from Public Health in America continue to be underrepresented in state law and suggest ways of closing these identified gaps in state legal authority for public health.

In first compiling the content of state public health law, the research team collected the enabling public health statutes from every state through on-line legal databases (eg, Westlaw, Lexis) and published compilations of state statutes. Refining its search methodology, the research team assembled a wide range of state enabling statutes for each state's health agency (many developed piecemeal over an extended period in the respective state's history) while excluding from analysis those statutes developed simply to specify an individual program or activity within the agency.

The research team then conducted a qualitative legal content analysis of these state statutes to determine the degree to which terms related to the mission or essential services of public health occur in the enabling portion of the statutes. To do so, the researchers employed the set of key identifying terms from the referenced 2000 study ${ }^{9}$ — coding through assigned objects of attention (nouns) and action directions (verbs) - to examine the enabling statutory language of the state public health laws and extract the terms related to the mission and essential services of the state health agency. Coding of each statutory passage was performed manually and independently by two legal researchers, each of whom was knowledgeable about public health law but was not involved in developing the mission and essential services of public health. Where there was disagreement on whether or not to include specific terms in the legal analysis, the principal investigator joined the coding process to ensure reliability and consistency and to identify consensus among the entire research team.

Drawing on the categorization process of the earlier study and the complete list of 6 mission statements and 10 essential services, the researchers categorized states by high, moderate, or low congruence with both the mission statements and essential services of public health, delineating these categories on the basis of the total number of related terms. As in the essential services categorizations of the 2000 study, ${ }^{9}$ state codification of public health services was classified as highly congruent statutes (HCS) for those enabling statutes that 
include 7 or more of the 10 essential public health services concepts, congruent statutes (CS) for those statutes that include between four and six concepts, and divergent statutes (DS) for those statutes that include zero to three concepts. Codification of mission statements for public health was classified as highly congruent mission statutes (HCM) for those enabling statutes that include three or more of the six public health mission concepts, congruent mission statutes (CM) for those statutes that include two concepts, and divergent mission statutes (DM) for those statutes that include zero to one concepts. Following these distinct categorization processes, the researchers examined congruence levels, comparing mission statement congruence and essential services congruence and analyzing the overlap between these principles of public health practice.

\section{Results-The Breadth of Public Health Agencies and Strength of Authority for Public Health Functions}

This categorization of congruence data-disaggregated by individual mission statement and essential service—is summarized in Table 2.

\section{Codifying the essential services of public health in state law}

With regard to state codification of the essential services of public health, 17 states are found to be highly congruent in their statutes (HCS); 26 states are congruent (CS); and 7 states are divergent (DS), with the states' collective incorporation of each essential public health service noted in Table 3.

Among the 17 HCS states, 4 have codified all 10 essential services concepts from Public Health in America, often doing so through law reform consistent with the Turning Point Act. Where the HCS states do not comprehensively cover every essential service in their enabling statutes (13 states), they most often exclude agency responsibility for research (11 states), a finding consistent with the tradition of research conducted by academic centers rather than state agencies; training the workforce (5 states); providing healthcare (6 states); and evaluating services (5 states), a newer concept for some governmental agencies. Despite these divergences, there has been universal enactment of statutory authority to diagnose problems and enforce laws among HCS states.

Extending the weaknesses of HCS states, there is complete exclusion of agency responsibility for research, training the workforce, and providing health-care among the seven DS states, adding to the HCS weaknesses a complete absence of public health authority for mobilizing community partnerships. Furthermore, only one of these seven DS states (a different state in each case) possessed authority for education and evaluation. Although these states did possess some statutory authority for the essential services of public health in their enabling statutes, these authorities were often restricted to policy development (five states) and law enforcement (six states), a finding consistent with traditional public health authorities limited to quarantine and isolation during infectious disease outbreaks.

\section{Codifying a public health mission in state law}

With regard to state codification of the public health mission statements, 22 states are highly congruent in their mission (HCM); 16 states are congruent $(\mathrm{CM})$; and 12 states are divergent (DM), with the states' collective incorporation of each public health mission statement noted in Table 4.

Forty-nine states have codified a mission to prevent epidemics, with DM states codifying this mission and nothing else. Where states did codify more than one mission statement, this mission was likely to be protecting against environmental hazards ( 24 states), a reflection of 
health departments that have retained authority for environmental health, followed by-in decreasing likelihood of incorporation—promoting healthy behaviors (14 states), responding to disasters (14 states), preventing injuries (10 states), and ensuring quality of health services (10 states).

\section{Comparing essential services and mission congruence}

In comparing the levels of congruence of essential services and mission statements, 14 states were found to be both HCS and HCM, with 3 states being HCS but not HCM and 8 states being HCM but not HCS, with this overlap of congruence noted in Table 5.

With the mutually reinforcing roles played by both mission statements and essential services in framing the statutory authority of the health agency, this finding is consistent with perceptions that mission statements, as broad statements of purpose, provide guidance to health agencies in the absence of explicit statutory authority for essential services.

\section{Discussion-Effect of the Turning Point Model State Public Health Act}

The 2000 study explicitly advocated that it serve as a "source[] of baseline data on existing statutes and also could form the baseline for monitoring changes in statues over time," noting contemporaneous efforts to strengthen the nation's public health infrastructurespecifically the Robert Wood Johnson Foundation's Turning Point Project. Much has changed since then. Beginning shortly after the baseline 2000 study, the Turning Point National Excellence Collaborative on Public Health Statute Modernization (Turning Point Collaborative $)^{22}$ brought together representatives from five key states and other federal, tribal, state, and local public health partners and private sector actors to transform and strengthen the legal framework for the public health system through the development of a model public health law. ${ }^{23}$ Following 3 years of development, the Turning Point Collaborative released the final version of this model-the Turning Point Act-in September 2003. The Turning Point Act, proposed as a model set of laws for modernization of state public health enabling statutes, includes in Section 2 the mission and essential services of public health agencies. ${ }^{14}$ Given the importance placed on the mission and essential services of public health in the Turning Point Act and the number of states that have since codified portions of the Turning Point Act in state law, it is clear that the Turning Point Act has had a dramatic impact in building the legal infrastructure for the mission and essential services of public health agencies.

Although the 2000 study found "no apparent relationship between the date of state adoption and the degree to which the statute contains concepts consistent with [Public Health in America]," (p53) recent reforms of state law consistent with the Turning Point Act show a high correlation with the mission and essential services of public health. As highlighted in legislative tracking of state public health law reforms consistent with the Turning Point Act, Section 2 of the Turning Point Act (2-101 Mission Statement, 2-102 Essential Public Health Services and Functions) has become the basis of statutory language for many recent state public health law reforms. ${ }^{24}$ In comparison with the results of the 2000 study (Table 6), these changes pursuant to the Turning Point Act have resulted in six additional states becoming highly congruent with essential public health services, with an additional three states becoming congruent. During this same time period, 12 additional states have become highly congruent in their mission, codifying those mission statements in state law (rather than informal mission statements). Despite a perceived risk of legislative "backsliding" in amending state public health authority (a fear that any attempts to modernize public health laws would expose existing laws to unwanted attention and consequent legislative retrenchment in the state's public health authority ${ }^{25}$ ), there is no evidence to support these 
fears, as no state has amended its laws to be less congruent with the concepts in Public Health in America.

An analysis of these reforms can facilitate the practice community's understanding of the relationship between public health laws and health agency performance, informing continuing efforts to modernize public health enabling statutes. As additional actors become aware of the Turning Point Act, examine their legal authority, and employ their leadership and advocacy to press for law reform, it is likely that additional states will codify the modern legal authority necessary to protect and promote the public's health. Given the applicability of the Turning Point Act as a force for institutionalizing this authority for the mission and essential services of public health, there is a greater need for the pubic health community to be aware of this model legal language as a tool to support the public health system.

\section{Conclusion}

These findings and analyses contribute to an understanding of the structure of health systems, public health statutory authority, and public health law modernization. Although many states may be operating in a manner consistent with the principles of the mission and essential services of public health, law reform - reflecting constituency expectations for public health-is crucial for the sustainability of agency efforts for disease prevention and health promotion. This update of earlier efforts to study public health enabling statutes is part of a larger research project to understand the relationship between the degree to which the statutes enabling the public health agency reflect the essential services of public health (reported here) and the level of public health system performance as reported in National Public Health Performance Standards (NPHPS) data, which are themselves based on the Public Health in America's essential services of public health. With the researchers hypothesizing that greater specificity of legal authority to deliver essential services will lead to greater likelihood that state and local health agencies will attend to these services, this subsequent study assesses how such statutory modernization efforts affect documented changes in the level of public health performance.

\section{Acknowledgments}

This study was supported by the National Network of Public Health Institutes as part of its research funding on the relationship between public health enabling statutes and system performance. In compiling and categorizing state public health enabling statutes, the authors are grateful for the research assistance of Demian Casey, MA, JD.

\section{References}

1. Institute of Medicine. The Future of the Public's Health in the 21st Century. Washington, DC: National Academy Press; 2003.

2. Gostin LO. Public health law reform. Am J Public Health. 2001; 91(9):1365-1368. [PubMed: 11527757]

3. Public Health Functions Steering Committee. Public Health in America. Washington, DC: USPHS Office of Disease Prevention and Health Promotion; 1994.

4. Turnock, BJ. Public Health: What It Is and How It Works. Gaithersburg, MD: Aspen Publications; 2004.

5. Institute of Medicine. The Future of Public Health. Washington, DC: National Academy Press; 1988.

6. Novick, LF.; Morrow, CB. A framework for public health administration and practice. In: Novick, LF.; Morrow, CB.; Mays, GP., editors. Public Health Administration: Principles for PopulationBased Management. Sudbury, MA: Jones \& Bartlett; 2007. 
7. NACCHO. Operational Definition of a Functional Local Health Department. Washington, DC: NACCHO; 2005.

8. National Association of Attorneys General (NAAG). Resolution Urging States to Review Their Public Health Laws. Resolution adopted, NAAG. Winter Meeting; Williamsburg, VA. December 26, 2003;

9. Gebbie KM. State public health laws: an expression of constituency expectations. J Public Health Manag Pract. 2000; 6(2):46-54. [PubMed: 10787778]

10. Beitsch LM, Brooks RG, Grigg M, Menachemi N. Structure and functions of state public health agencies. Am J Public Health. 2006; 96(1):167-172. [PubMed: 16317210]

11. Goodman, RA.; Kocher, PL.; O'Brien, DJ.; Alexander. The structure of law in public health systems and practice. In: Hoffman, RE.; Lopez, W.; Matthews, GW.; Rothstein, MA.; Foster, KL., editors. Law in Public Health Practice. New York, NY: Oxford University Press; 2007. p. 45-68.

12. Institute of Medicine. Who Will Keep the Public Healthy? Educating Public Health Professionals for the 21st Century. Washington, DC: National Academy Press; 2003. Committee on Educating Public Health Professionals for the 21st Century.

13. Erickson DL. The public health statute modernization national collaborative: developing a model state public health law. J Public Health Manag Pract. 2002; 8(1):39-46. [PubMed: 11789037]

14. Turning Point Public Health Statute Modernization National Collaborative. [Accessed April 25, 2009] Turning Point Model State Public Health Act. http://www.hss.state.ak.us/dph/improving/ turningpoint/MSPHA.htm. Published 2003

15. Centers for Law and the Public's Health: A Collaborative at Johns Hopkins and Georgetown Universities. [Accessed March 10, 2008] Model State Emergency Health Powers Act. Published 2001. http://www.publichealthlaw.net/MSEHPA/MSEHPA2.pdf

16. Gostin LO, Sapsin JW, Teret SP, et al. The Model State Emergency Health Powers Act: planning for and response to bioterrorism and naturally occurring infectious diseases. JAMA. 2002; 288:622-628. [PubMed: 12150674]

17. Erickson DL, Gostin LO, Street J, Mills SP. The power to act: two model state statutes. J Law Med Ethics. 2002; 30(3):57-62. [PubMed: 12508504]

18. Centers for Law and the Public's Health. [Accessed April 12, 2008] A Collaborative at Johns Hopkins and Georgetown Universities. Model state public health laws. http:// www.publichealthlaw.net/Resources/Modellaws.htm

19. Meier BM, Hodge JG, Gebbie KM. Report from the field: Alaska public health law reform. J Health Polit Policy Law. 2008; 33(2):281-293. [PubMed: 18325901]

20. Baker EL, Blumenstock JS, Jensen J, Morris RD, Moulton AD. Building the legal foundation for an effective public health system. J Law Med Ethics. 2002; 30(3):48-51. [PubMed: 12508502]

21. Beaulieu J, Scutchfield FD. Assessment of validity of the National Public Health Performance Standards: the local public health performance assessment instrument. Public Health Rep. 2002; 117:28-36. [PubMed: 12297679]

22. Hassmiller S. Turning point: the Robert Wood Johnson Foundation's effort to revitalize public health at the state level. J Public Health Manag Pract. 2002; 8(1):1-5. [PubMed: 11789031]

23. Hodge JG, Gostin LO, Gebbie K, Erickson DL. Transforming public health law: the Turning Point Model State Public Health Act. J Law Med Ethics. 2006; 34(1):77-84. [PubMed: 16489986]

24. Centers for Law and the Public's Health: A Collaborative at Johns Hopkins and Georgetown Universities. [Accessed April 12, 2008] The Turning Point Model State Public Health: Legislative Status Update. http://www.publichealthlaw.net/Resources/Modellaws.htm\#TP

25. Meier BM, Hodge JG, Gebbie KM. Transitions in state public health law: comparative analysis of state public health law reform efforts following the Turning Point Model State Public Health Act. Am J Public Health. 2009; 99(3):423-430. [PubMed: 19150900]

\section{Biographies}

Benjamin Mason Meier, LLM, MPhil, JD, Assistant Professor of Global Health Policy, University of North Carolina at Chapel Hill, has developed expertise in the political processes of domestic and international public health law reform. His current empirical 
research at the intersection of law and public health explores public health enabling statutes, hospital-acquired infection reporting, emergency preparedness law, clinical research regulation, global health governance, and the human right to health.

Jacqueline Merrill, DNSC, RN, Department of Biomedical Informatics, Columbia University, is a public health services researcher trained in public health informatics. An academic with 6 years' experience at the New York City Department of Health, her expertise inlcudes public health organizational systems, information management, workforce development and preparedness, information display and access, communications, and competency-based training.

Kristine M. Gebbie, DrPH, RN, Joan Grabe Dean (Acting) of the School of Nursing, City University of New York, Hunter-Bellevue School of Nursing, has long-standing experience in public health systems research, public health law, and competency-based public health and has published landmark research at the intersection of these topics. This work and her previous government service in local, state, and national public health policy-making provide Dr Gebbie with a unique understanding of the circumstances involved in collecting and disseminating information on laws and regulations. 

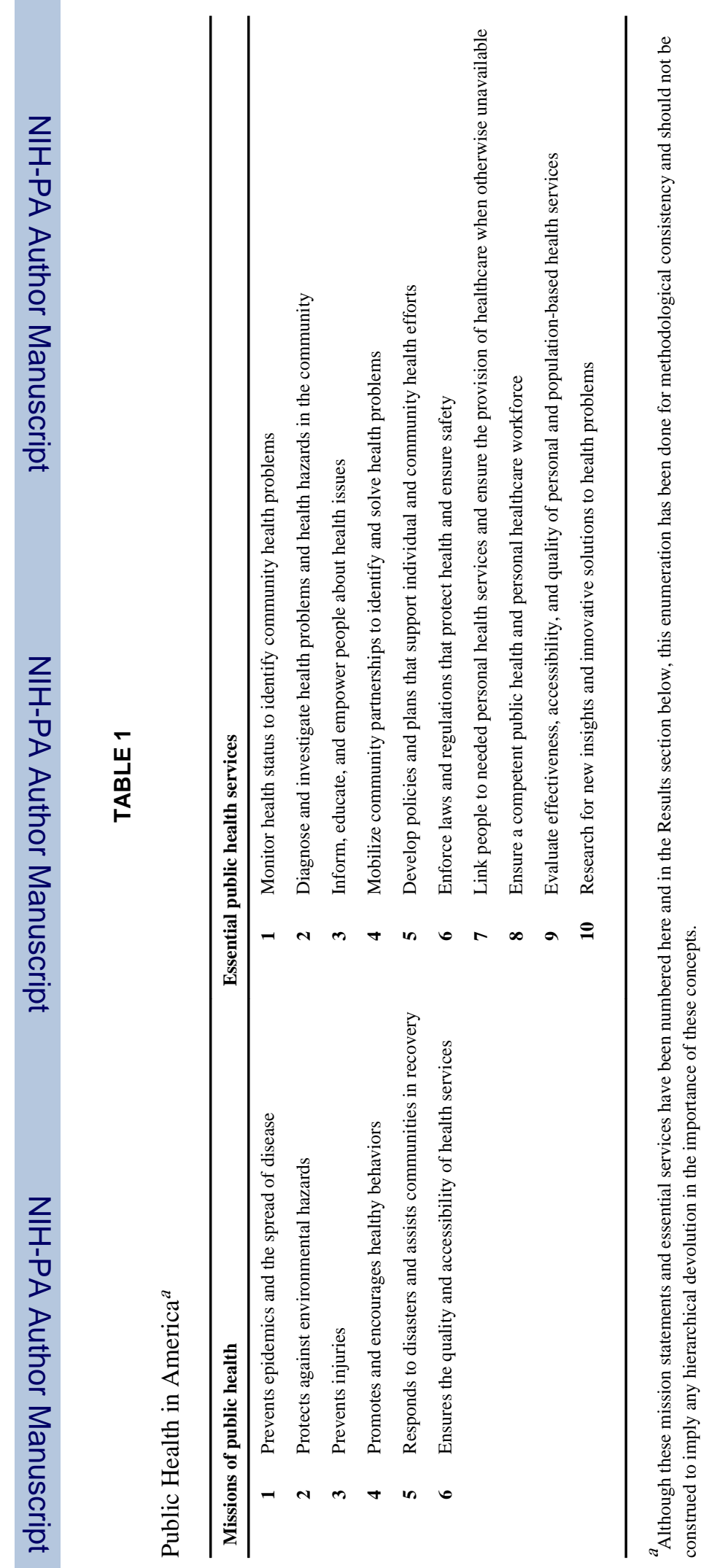

J Public Health Manag Pract. Author manuscript; available in PMC 2013 July 29. 


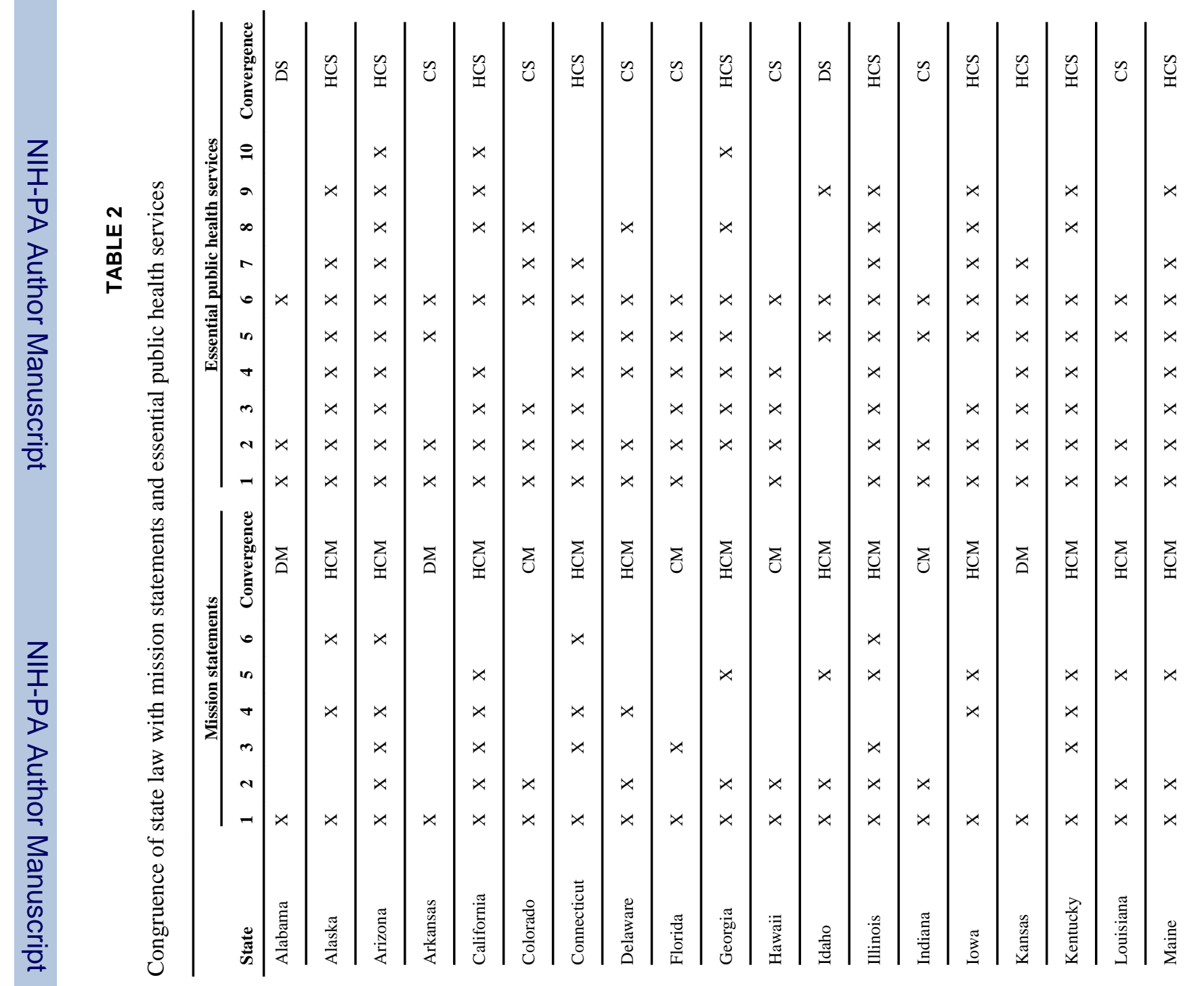


Meier et al.

Page 11

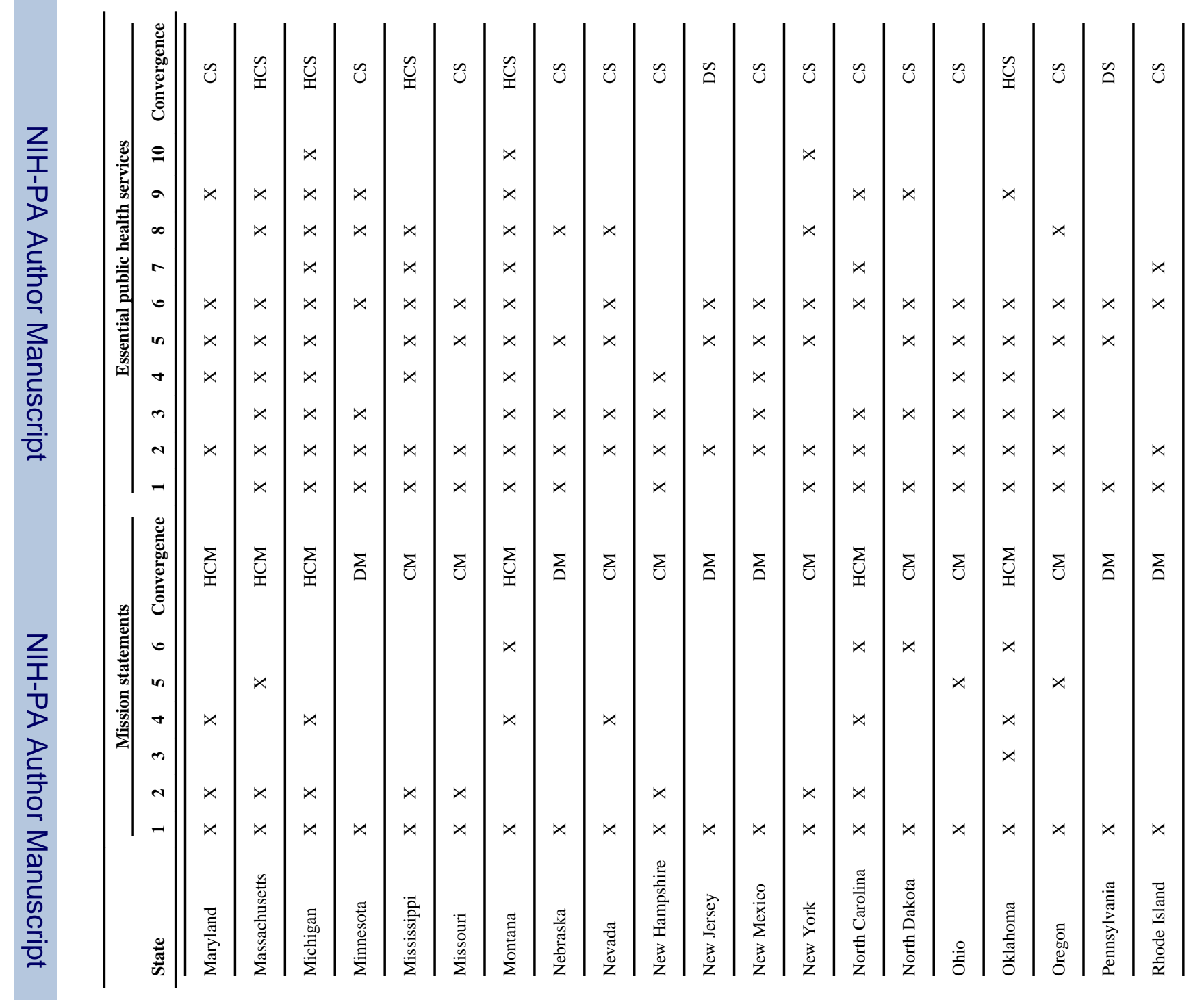

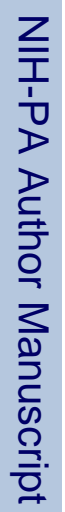




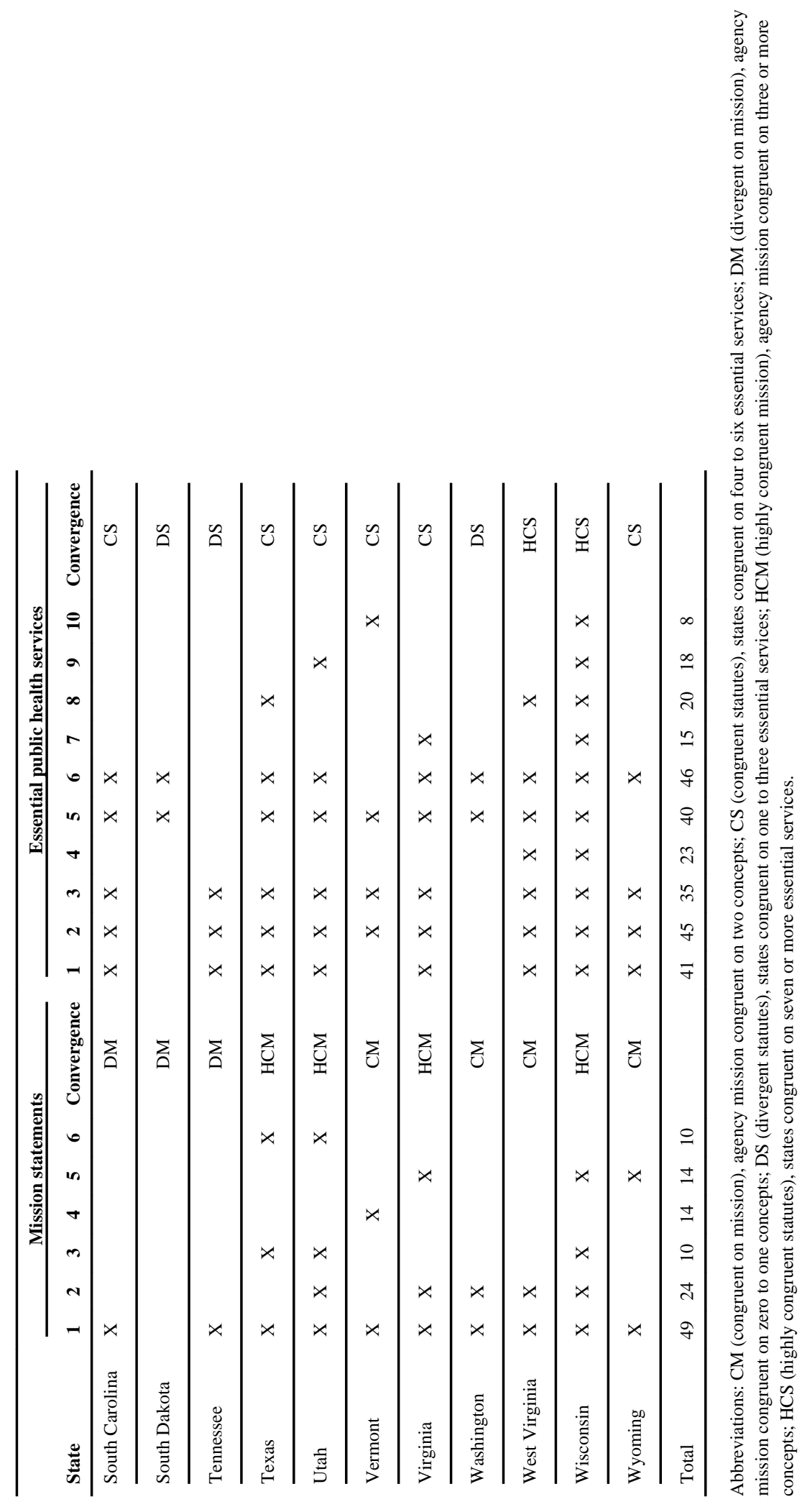

J Public Health Manag Pract. Author manuscript; available in PMC 2013 July 29. 


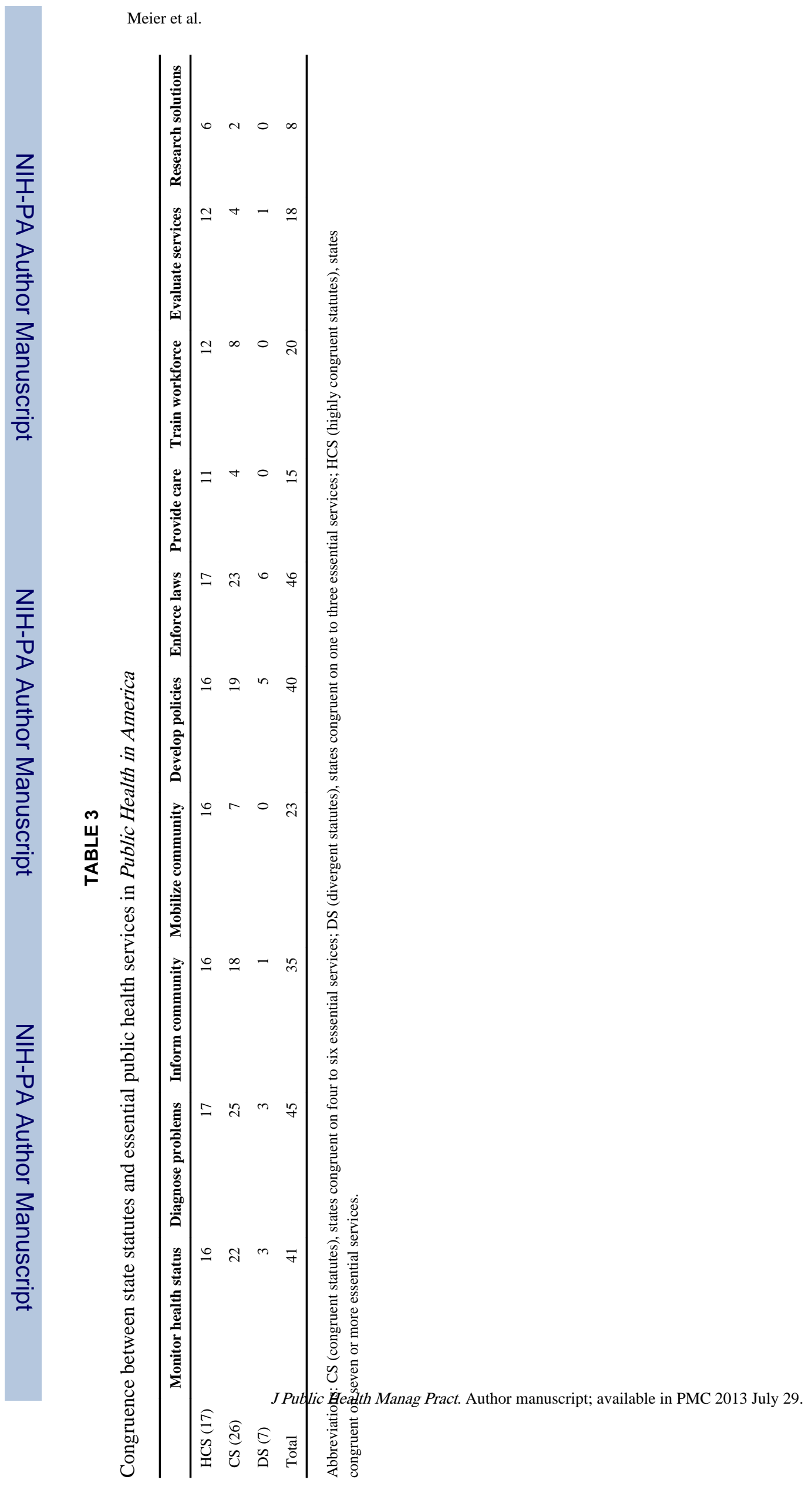

Page 13 


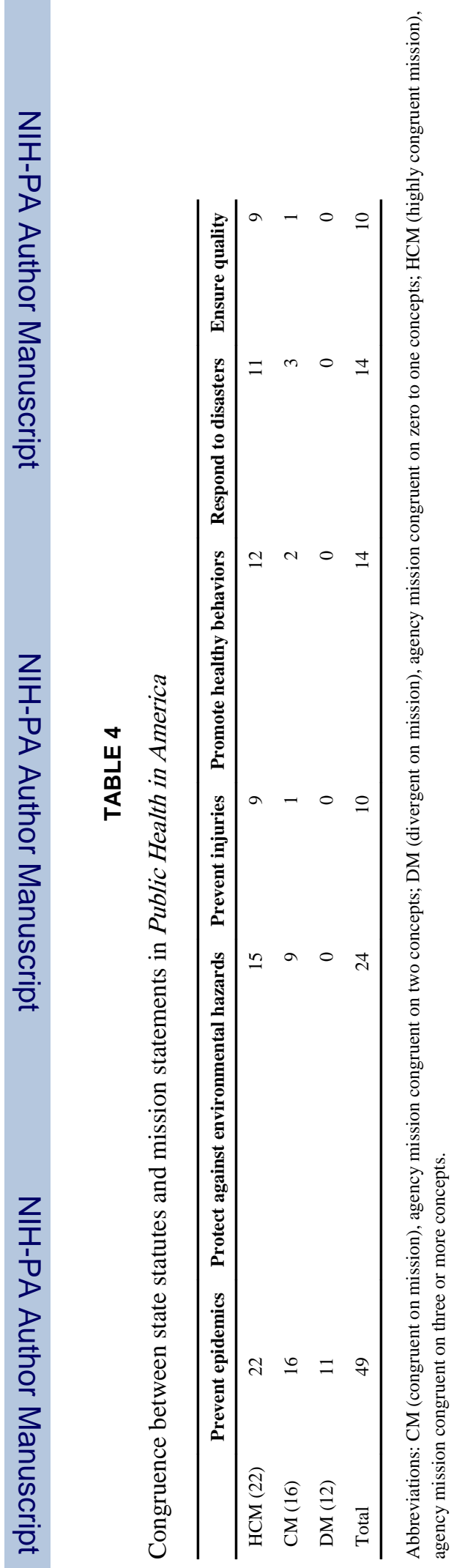

J Public Health Manag Pract. Author manuscript; available in PMC 2013 July 29. 


\section{TABLE 5}

Relationship between congruence in essential services and congruence in mission statements

\begin{tabular}{lrrc}
\hline & HCS & CS & DS \\
\hline HCM & 14 & 7 & 1 \\
CM & 2 & 13 & 1 \\
DM & 1 & 6 & 5 \\
\hline
\end{tabular}

Abbreviations: CM (congruent on mission), agency mission congruent on two concepts; CS (congruent statutes), states congruent on four to six essential services; DM (divergent on mission), agency mission congruent on zero to one concepts; DS (divergent statutes), states congruent on one to three essential services; HCM (highly congruent mission), agency mission congruent on three or more concepts; HCS (highly congruent statutes), states congruent on seven or more essential services. 
